\title{
Sekonder Osteoporoz Nedeni Marfan Sendromu: Olgu Sunumu
}

\author{
Secondary Osteoporosis as a Result of Marfan Syndrome: A Case Report
}

Beril Doğu, Jülide Öncü, Hülya Şirzai, Figen Yılmaz, Banu Kuran

Şişli Etfal Eğitim ve Araştırma Hastanesi, Fizik Tedavi ve Rehabilitasyon Kliniği, ìstanbul, Türkiye

\section{Özet}

Marfan sendromu (MFS) 15. krozomdaki fibrillin-1 gen mutasyonu sonucu gelişen otozomal dominat bir hastalık olup, kas-iskelet sistemi, kardiyovasküler, oküler ve nörolojik sistem problemlerine sebep olan multisistemik bir bağ dokusu hastalığıdır. MFS ayrıca sekonder osteoporoz nedeni olup, kemik mineral yoğunluğunda (KMY) azalma ve kırık riskinde artışa yol açar. Bu yazıda bel ve sağ bacakta ağrı yakınması ile polikliniğimize başvuran 29 yaşındaki erkek hastanın yapılan KMY ölçümünde azalma tespit edilmesi nedeniyle MFS'nin sekonder osteoporoz nedenlerinden biri olduğuna ve osteoporoz gelişiminin sebeplerine dikkati çekmek amaçlanmıştır. (Türk Osteoporoz Dergisi 2012;18: 68-71)

Anahtar kelimeler: Marfan sendromu, osteoporoz

\section{Summary}

Marfan syndrome (MFS) is an autosomal dominant disorder developing as a result of mutation of fibrillin-1 gene located on chromosome 15. This collagen vascular disease causes multisystem abnormalities involving musculoskeletal, cardiovascular, ocular, and neurologic systems. MFS also causes secondary osteoporosis, and leads to a decrease in bone mineral density (BMD), and an increase in fracture risk. In this report, we aimed to point out that MFS is a cause of seconder osteoporosis and the reason for developing osteoporosis in general by examining the case where a 29 year old male MFS patient who visited our outpatient clinics with complaints of low back, and right leg pain exhibited decrease in BMD. (Turkish Journal of Osteoporosis 2012;18: 68-71)

Key words: Marfan syndrome, osteoporosis

\section{Giriş}

Illk olarak pediatri profesörü Antoine-Bernard Marfan tarafından 5 yaşındaki bir kız çocuğunda uzun ince parmaklar ve iskelet anomalileri olarak tariflenen MFS (1), 15. kromozomdaki fibrillin-1 gen mutasyonu sonucu gelişen, her iki cinsiyeti etkileyen, otozomal dominant geçiş gösteren, mutisistemik konnektif doku hastalığıdır $(2,3)$. \%25-\%30 olguda sporodik mutasyonlar görülebilir (4). Prevalansı 10.000'de 2-3 kişi olarak değişmektedir $(5,6)$.

MFS'nin major klinik bulguları kardiyovasküler, oküler ve iskelet sisteminden oluşan 3 major sistem tutulumu ile ilgilidir $(5,7)$. Potansiyel kardiyovasküler sistem patolojileri aort dilatasyonu, mitral kapak prolapsusu, pulmoner arter dilatasyonu, aort diseksiyonu, atrial septal defekt, patent duktus arteriosus gibi sıklıkla yaşamı tehdit edebilen patolojilerdir $(5,8)$. Oküler sistemde miyopi, astigmatizm gibi kırma kusurları sık olarak görülürken, \%60 hastada lens ektopisi gözlenir. Bu hastalarda retinal ayrılma, glokom, erken katarakt gelişimi riski artmıştır $(4,8,9)$. İskelet sistemi bulguları ise artmış boy ve kol uzunluğu, göğüs deformiteleri (pektus ekskavatum veya karinatum), eklem laksitesi, vertabral kolon deformiteleri (skolyoz veya torasik lordoz), yüksek damak, dar çene, pes planus, araknodaktili, asetabular protrüzyon ve $\mathrm{KMY}^{\prime}$ de azalmadır $(2,4,5,8,10)$. Ayrıca bel ve proksimal bacak ağrısı, güçsüzlük, his kaybına neden olan dural ektazi (dural sakın gerilmesi) gibi sinir sistemi, spontan pnömotoraks ve bül oluşumu gibi pulmoner sistem, stria ve rekürren herniasyon oluşumuna neden olan cilt patolojileri de diğer sistem tutulumlarıdır $(4,5,11)$.

Aort diseksiyonu, konjestif kalp yetmezliği, kalp kapağı hastalıkları \%90 fazladan hastada ölüm nedenidir (12). Son yıllarda $\beta$ bloker ve 
kalsiyum kanal blokerlerinin kullanımı, uygulanan kardiyotorasik cerrahi yöntemler neticesinde kardivasküler komplikasyonlar önlenerek MFS'de beklenen yaşam ömrü uzatılmştır $(5,12)$. Bu nedenle hayatta kalan hastalarda, hastaların morbiditelerini en aza indirerek yaşam kalitelerini arttırmak önemlidir.

Osteoporoz tedavi edilmediği takdirde kırıklarla sonuçlanan, hastalarda ağrı ve yaşam kalitesinde azalmaya neden olabilen, tanı ve tedavisi mümkün bir hastalıktır. Bu yazıda MFS olan hastamızda saptadığımız KMY azalmasına dikkat çekmek için, olgumuza yaklaşımımızı sunmayı ve MFS'de osteoporoz nedenleri ile izlemde dikkat edilecek noktaları literatür eşliğinde irdelemeyi amaçladık.

\section{Olgu}

Bel ve sağ bacakta ağıı yakınması ile polikliniğimize başvuran 29 yaşındaki erkek hasta, 3-4 aydır olan mekanik karakterde ağrı tarifliyordu. Olgumuz uzun boylu, zayıf yapıda olup tipik MFS görünümüne sahipti. Dorsalde açıklığı sağa, lomberde açıklığı sola bakan skolyozu mevcuttu (Resim 1 ve 2). Yapılan muayenesinde bel hareketleri tüm yönlere açık ama ağrılı, sinir germe testleri negatif ve nörolojik defisiti yoktu. Özgeçmişinde nefrolitiazis öyküsü mevcuttu. Ayrıca assendan aort anevrizması ve aort yetmezliği nedeniyle opere edilmiş olup, warfarin sodyum $5 \mathrm{mg} /$ gün (Coumadin, Eczacıbaşı) ve metoprolol süksinat 50 mg/gün (Beloc ZOK, AstraZeneca) kullanmaktaydı. Daha önceden yapılmış olan

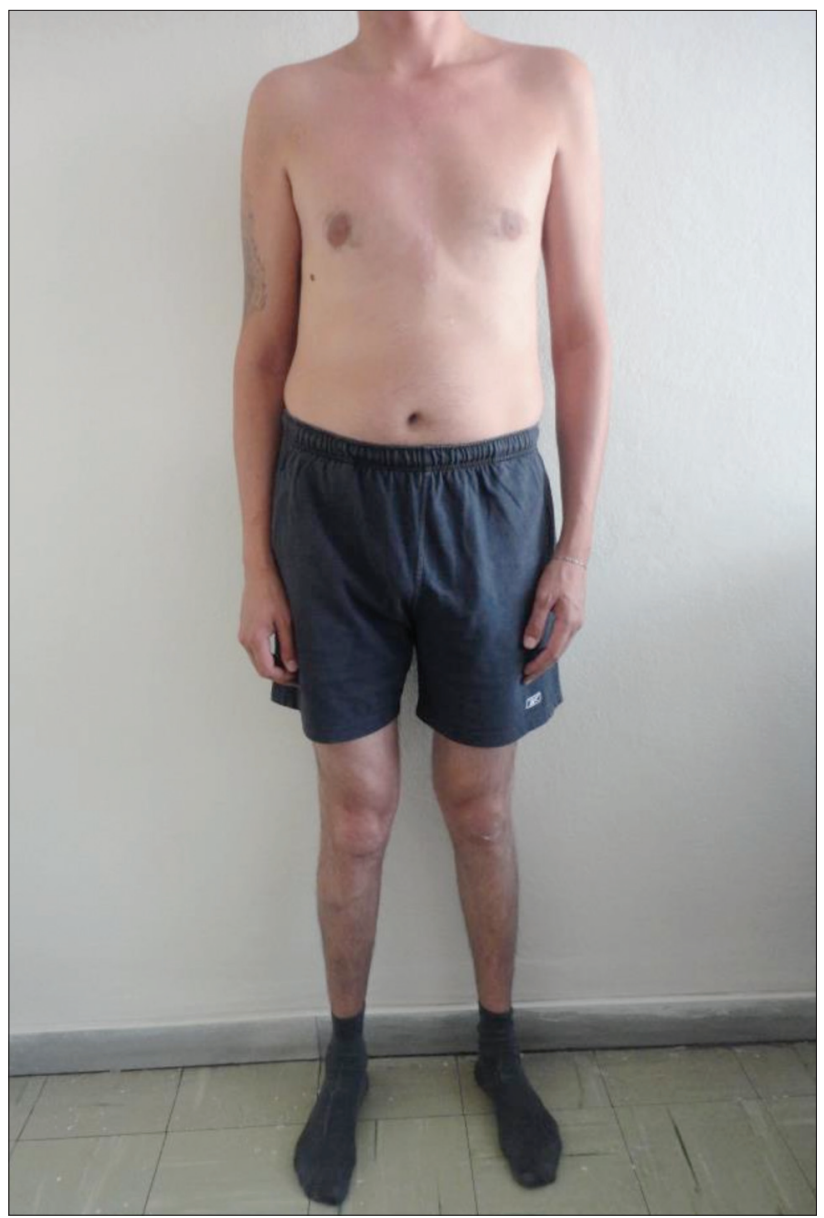

Resim 1. Hastanın anteriordan görünüşü
MRG'de spinal kanalda ileri derecede genişlemeye neden olan perinöral kistler izlenmekte olup, bel ve sağ bacak ağıısını açıklayacak kök basısı yoktu.

Olgunun MFS olması nedeniyle bu hastalığın sekonder osteoporoza sebep olabileceğini düşündüğümüz için hastamızda osteoporoz varlığını araştırdık. Bu amaçla hastamızın KMY Ölçümünü ve laboratuvar tetkiklerini yaptık. KMY ölçümleri $\left(\mathrm{gr} / \mathrm{cm}^{2}\right)$ DXA tekniği (Lunar Prodigy Advance, GE, Madison, WI USA) ile yapıldı. L2-L4 KMY $0.857 \mathrm{gr} / \mathrm{cm}^{2}$, z skoru -3.1; femur boyun KMY $0.911 \mathrm{gr} / \mathrm{cm}^{2}$, z skoru -1.2; femur total KMY 0.721 $\mathrm{gr} / \mathrm{cm}^{2}$ z skoru -2.6 idi. Laboratuar testlerinde akut faz reaktanları, hemogram ve kan biyokimya değerleri normal iken 24 saatlik idrar kalsiyum ve fosfor değerleri ise yüksekti (sırasıyla 520 mg/gün ve $1340 \mathrm{mg} /$ gün).

Olgunun başvuru nedeni olan bel ve bacak ağrısına yönelik fizik tedavi ve egzersiz programı düzenlendikten sonra yaşa göre beklenenden düşük KMY olduğu için $70 \mathrm{mg} / \mathrm{hafta}$ alendronat tedavisine başlayarak osteoporoz polikliniğimizde takibe alındı. Tedavinin 1. yılında KMY ölçümünü tekrarlandı ve L2-L4 KMY 0,956 $\mathrm{gr} / \mathrm{cm}^{2}$, z skoru -2,5, femur boyun KMY 0,841 gr/ $/ \mathrm{cm}^{2}$, z skoru -1,8; femur total KMY $0,770 \mathrm{gr} / \mathrm{cm}^{2}$ z skoru $-2,3$ olarak saptand. Olgumuzun genç ve aktif olması, daha önce geçirilmiş osteoporotik kırık öyküsü olmaması nedeniyle besinlerle takviye ve egzersizler konusunda önerilerde bulunarak ilaçsız takibe aldık. Bir yıllık takip sonrasında KMY ölçümünü tekrar yaptııılı. L2-L4 KMY 0,957

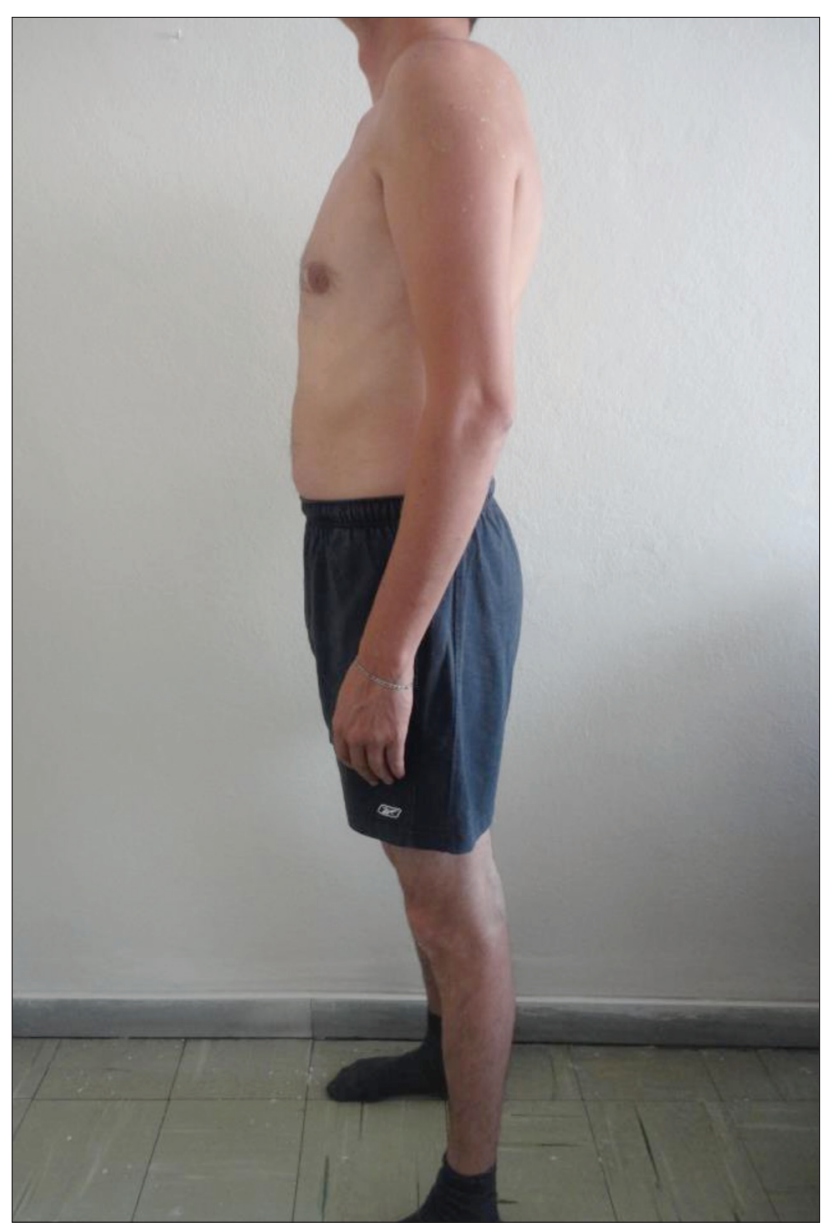

Resim 2. Hastanın lateralden görnüşü 
$\mathrm{gr} / \mathrm{cm}^{2}$, z skoru -2,6, femur boyun KMY 0,800 gr/cm², z skoru -2,1; femur total KMY $0.767 \mathrm{gr} / \mathrm{cm}^{2}$ z skoru -2,3 olarak bulunarak vertebra ve femur KMY'de azalma olduğu görüldü (Tablo 1). Olgumuz ilaçsız kaldığı süre içinde KMY'de azalma olması, hem hastalığının hem de kullandığı oral antikoagülan tedavinin osteoporoza yol açması nedeniyle tekrar alendronat $70 \mathrm{mg} /$ hafta başlandı.

\section{Tartışma}

MFS fibrillin-1 genindeki mutasyon sonucu gelişen multisistemik bir bağ dokusu hastalığı olup, hastalardaki genetik ve biyokimyasal defektler KMY'nin azalmasına ve kırık riskinde artışa sebep olabilmektedir. Fibrillin-1 glikoprotein olup, kemik dahil bir çok konnektif dokuda bulunur. İnsan kültürlerinde periostun dış yüzünde ve yeni kemik yüzeyindeki osteoblastik tabakada elde edilmiştir (5). Fibrilin EGF'ye benzer kısım, 8-sistein rezidü kısımlarından ve TGF- $\beta$ bağlayan proteinlerden oluşur. MFS'da fibrillin EGF kısımlarında mutasyonlar görülmüş olup, Ca bağlanmasını bozarak doruk kemik kütlesinde azalmaya neden olduğu belirtilmektedir $(5,9,13)$.

Düşük doruk kemik kütlesi osteoporoz için bir risk faktörüdür (14). Çocukluk ve büyüme çağlarında doruk kemik kütlesinin oluşumunda egzersiz ve Ca tüketimi önemli faktörlerdir. Bu hastalar çocukluk ve genç erişkinlik dönemlerinde kas iskelet sistemi ağıları ve aort rüptürü riski nedeniyle yarışmalı sporlardan kaçınmaları tavsiye edildiği için egzersiz yapmaları kısıtlanarak iskelet yüklenmesi az olur. Bu nedenle MFS'li çocuklarda yeterli kemik kütlesi oluşamayabilir (13).

Osteoporoza neden olabilecek bir diğer faktör ise bizim hastamızda olduğu gibi kardiyovasküler komplikasyonların önlenmesi amacıyla kullanılan antikoagülan tedavilerdir. Warfarin gibi oral antikoagülanlar vitamin K'nın geri dönüşümünü engelleyerek, vitamin $K$ antagonisti olarak görev alırlar. Vitamin $\mathrm{K}$ ise aynı zamanda gamma-karboksi glutamat sentezlenmesinde rol oynar. Osteokalsinde gamma-karboksi glutamat içerir ve karboksillenmiş osteokalsin kemiğin hidroksi apatit matriksine kalsiyum bağlanması ile aktive olarak kemik formasyonunda major rol oynar. Warfarinin vitamin K'yı inhibe etmesi ile osteokalsinin karboksilasyonu engellenecektir. Sonuçta vitamin K'nın KMY üzerinde pozitif etki yaratarak kırık riskini azaltma özelliği ortadan kalkacaktır $(15,16)$.

Carter ve ark. (13) MFS olan 25 erişkin hasta ile yaptıkları çalışmada yaş ve cinsiyet eşleştirilmiş sağlıklı kontrollere göre KMY'nin lomber ve femurda azaldığını, cinsiyetlere göre alt grup analizleri yapıldığında ise kadınlarda femur boyun ve totalde azalma olurken, erkeklerde yalnızca femur boynunda istatistiksel olarak azalma tespit ettiklerini, vertebra ve femur totalde azalma olmakla beraber bunun istatistiksel anlamlılığa ulaşmadığını belirtmişlerdir (13). Moura (3) ve Le Parc ve ark. (17) her iki cinsiyette kalça ve el bilek KMY'de azalma olduğunu bu kaybın kortikal kemikte daha belirgin olduğunu belirtmişlerdir. Başka bir çalışma da ise erkek MFS hastaların kadın MFS hastalarına göre KMY değerlerini femur ve tüm vücut ölçümlerinde daha düşük bulmuşlar, sağlıklı gönüllülerle karşılaştırdıklarında ise kadınlar normal sınırlar içinde bulunurken, erkeklerde femur boynunda osteopeni bulduklarını belirtmişlerdir (5). Bizim olgumuzda ise hem vertebra hem de femur KMYölçümlerinde azalma mevcuttu. Olgumuza 1 yıl alendronat tedavisi verdiğimizde KMY'nin hem femur total hem de vertebral KMY'sinde artış olduğunu, ancak bu etkinin 1 yıllık ilaçsız takip sürecinde tekrar azalma gösterme eğiliminde olduğunu gözlemledik. Olgumuzun genç, aktif olmasına ve kırık öyküsünün olmamasına rağmen ilaçsız kaldığı dönemde tekrar KMY'sinde azalma olduğu, buna hastalığının ve kullanmaya devam ettiği oral antikoagülan tedavinin neden olabileceği düşünülerek z skoru beklenen yaş ile uyumlu kabul edilen -2 ve üzeri değere ulaşana kadar ilaç kullanmasının uygun olacağına karar verilerek tekrar alendronat tedavisine başladık.

Bu hastalarda osteoporoz tedavisindeki zorlukların yanı sıra literatürde MFS'de hastaların uzun boylu, uzun kemikli ve düşük yağ oranlı olması nedeniyle KMY ölçüm sonuçlarını DXA cihazının dataları ile karşılaştırmanın yanıltıcı sonuçlara neden olabileceğine dair görüşler bulunmaktadır (18). Giampietro ve ark. MFS'li hastaların uzun boylu olmaları nedeniyle artefaktlara sebep olup, ölçüm sonuçlarında hatalara neden olabileceğini, ayrıca DXA'nın vertebranın enini ve boyunu ölçerek alansal bir ölçüm yaptığını ancak vertebral hacmi değerlendirmediğini, MFS'de ise yaş, cinsiyet, boy ve kilo eşleşmiş kontrollere göre vertebranın boyu, kesitsel alanı gibi morfolojik özelliklerin farklı olabileceği nedeniyle iskelet büyüklüğünden etkilenmeyen QCT ile 3 boyutlu ölçüm yapmanın daha doğru sonuçlar verebileceğini vurgulamışlardır $(5,19)$.

Osteoporozun istenmeyen bir sonucu kırıklara neden olmasıdır. MFS'de ise kırıklarda artış olduğuna dair çelişkili sonuçlar bulunmaktadır. Aynı grubun 2 farklı çalışmasında travma ile ilişkili veya düşük enerjili kırık oranı \%10 ve \%24.6 olarak belirtilirken $(3,17)$, MFS'li hastalarda kırık riskinde belirgin artış görülmeyen yayınlar bulunmaktadır (5). Hindocha ve ark. MFS olan bir olgularında femur boynunda atravmatik kırık geliştiğini, azalmış KMY'nin atravmatik kırıklar için MFS'de risk faktörü olabileceğini belirtmişlerdir (20).

Tablo 1. Osteoporoz hastalarının yaș, boy, ağırlık, VKi değerlerinin karșılaștırılması

\begin{tabular}{|l|c|c|c|}
\hline & $\begin{array}{c}\text { Başlangıç } \\
\text { (Tedavi öncesi) }\end{array}$ & $\begin{array}{c}\text { I, Kontrol } \\
\text { (1yıllık tedavi sonrası) }\end{array}$ & $\begin{array}{c}\text { II, Kontrol } \\
\text { (1 yıllık ilaçsız dönem sonrası) }\end{array}$ \\
\hline L2-L4 KMY $\left(\mathrm{gr} / \mathrm{cm}^{2}\right)$ & 0,857 & 0,956 & 0,957 \\
\hline L2-L4 Z skor & $-3,1$ & $-2,5$ & $-2,6$ \\
\hline Femur boyun KMY $\left(\mathrm{gr} / \mathrm{cm}^{2}\right)$ & 0,911 & 0,841 & 0,800 \\
\hline Femur boyun Z skor & $-1,2$ & $-1,8$ & $-2,1$ \\
\hline Femur total KMY $\left(\mathrm{gr} / \mathrm{cm}^{2}\right)$ & 0,721 & 0,770 & 0,767 \\
\hline Femur total Z skor & $-2,6$ & $-2,3$ & $-2,3$ \\
\hline
\end{tabular}


Sonuç olarak MFS çok çeşitli iskelet sistemi anomalilerinin yanı sıra KMY'da azalmaya neden olan sebep olan bir hastalıktır. Bu hastalarda kemik kaybını engellemek ve tedavi etmek için geliştirilmiş önerilere intiyaç vardır.

\author{
Kisaltmalar \\ MFS: Marfan sendromu \\ KMY: Kemik mineral yoğunluğu \\ DXA: Dual enerji X-Ray absorbsiyometri \\ mg: miligram/gün \\ mg/gün: miligram/gün \\ gr: gram \\ $\mathrm{cm}^{2}$ : santimetrekare \\ MRG: Manyetik rezonans görüntüleme \\ EGF: Epidermal growth faktör \\ TGF- $B$ : Transforming growth faktör- $B$
}

\section{Kaynaklar}

1. Raanani E, Ghosh P. The multidisciplinary approach to the marfan patient. Isr Med Assoc J 2008;10:171-74.

2. Jones KB, Sponseller PD, Erkula G, Sakai L, Ramirez F, Dietz HC 3rd, et al. Symposium on the musculoskeletal aspects of Marfan syndrome: Meeting report and state of Science. J Orthop Res 2007; 25:413-22.

3. Moura B, Tubach F, Sulpice M, Boileau C, Jondeau G, Muti C, et al. Bone mineral density in Marfan syndrome. A large case-control study. J Bone Spine 2006;73:733-35. Epub 2006 Sep 14.

4. Yuan SM, Jing H. Marfan's syndrome: an overview. Sao Paulo Med 2010:128:360-6.

5. Giampietro PF, Peterson M, Schneider R, Davis JG, Raggio C, Myers $E$, et al. Assessment of bone mineral density in adults and children with Marfan syndrome. Osteoporosis Int 2003;14:559-63. Epub $2003 \mathrm{Jul} 3$
6. Judge DP, Dietz HC. Marfan's syndrome. Lancet 2005;366:1965-76

7. Gray $J R$, Bridges $A B$, Mole $P A$, Pringle $T$, boxer $M$, Paterson $C R$. Osteoporosis and Marfan syndrome. Postgrad Med J 1993;69:373-75.

8. Frydman M. The marfan syndrome. Isr Med Assoc J 2008;10:175-8.

9. Lebreiro A, Martins E, Cruz C, Almeida J, Maciel MJ, Cardoso JC, Lima CA. Marfan syndrome: clinical manifestations, pathophysiology and new Outlook on drug therapy. Rev Port Cardiol 2010;29:1021-36.

10. Avivi E, Arzi H, Paz L, Caspi I, Checkik A. Skeletal manifestations of marfan syndrome. Isr Med Assoc J 2008;10:186-8.

11. Dean JC. Marfan syndrome: clinical diagnosis and management. Eur J Hum Genet 2007;15:724-33. Epub 2007 May 9.

12. Ha HI, Seo JM, Lee SH, Kang JW, Goo HW, Lim TH, et al. Imaging of marfan syndrome: multisystemic manifestations. Radiographics 2007:27:989-1004.

13. Carter N, Duncan E, Wordsworth P. Bone mineral density in adults with Marfan syndrome. Rheumatology (Oxford) 2000;39:307-9.

14. Uçan Ö, Taşcı S, Ovayolu N. Osteoporozda risk faktörleri ve korunmanın önemi. Fırat Sağlık Hizmetleri Dergisi 2007;2:73-86.

15. Woo C, Chang LL, Ewing SK, Bauer DC. Single-point assessment of warfarin use and risk of osteoporosis in elderly men. J Am Geriatr Soc 2008:56:1171-6.

16. Pearson DA. Bone health and osteoporosis: the role of vitamin $\mathrm{K}$ and potential antagonism by anticoagulants. Nutr Clin Pract 2007:22:517-44.

17. Le Parc JM, Plantin P, Jandeau G, Goldschild M, Albert M, Boilequ C. Bone mineral density in sixty adult patients with Marfan syndrome. Osteoporosis Int 1999;10:475-9.

18. Le Parc JM, Molcard S, Tubach F. Bone mineral density in Marfan syndrome. Rheumatology (Oxford) 2001;40:358-9.

19. Giampietro PF, Peterson MG, Schneider R, Davis JG, Burke SW, Boachie-Adjei $\mathrm{O}$, et al. Bone mineral density determinations by dual energy $x$-ray absorptiometry in the management of patients of patients with Marfan syndrome-some factors which affect the measurement. HSS J 2007:3:89-92.

20. Hindocha $S$, Kershaw $S$, Clayson AD. Atraumatic fracture neck of femur in marfan's syndrome: a case report. Injury Extra 2007:38:343-5. 